\title{
Aplikasi Sticker Motor Scoopy Berbasis Android (Studi Kasus CV. Upgrade Graphic Design)
}

\author{
Ana Yulianti ${ }^{1}$, Taufik Akbar ${ }^{2}$, Abdul Syukur ${ }^{3}$ \\ Program Studi Teknik Informatika, Fakultas Teknik, Universitas Islam Riau ${ }^{1,2,3}$ \\ ana.yulianti@eng.uir.ac.id ${ }^{1}$, taufikakbar@student.uir.ac.id ${ }^{2}$, abdulsyukur@eng.uir.ac.id ${ }^{3}$
}

\section{Article Info}

History :

Dikirim 01 Maret 2018

Direvisi 03 November 2018

Diterima 16 Maret 2019

\section{Kata Kunci:}

Sticker Motor Scoopy

Blender

3D

Unity3D

C\# (C Sharp)

\begin{abstract}
Abstrak
CV Upgrade Graphic Design, perusahaan yang bergerak dalam bidang periklanan, utamanya di material cutting sticker, sticker printing, one way, vision, sticker sablon, sticker poliplex, dan segala jenis sticker. Media promosi yang digunakan oleh banyak perusahaan sticker saat ini masih banyak yang hanya menampilkan hasil design dalam bentuk dua dimensi (2D) pada objek motor atau sekedar print out dalam bentuk kertas hingga banyak konsumen yang kurang puas dengan hasil design yang ditampilkan tersebut. Penelitian ini membuat hasil design yang di tampilkan dalam bentuk tiga dimensi (3D) menggunakan aplikasi blender dan seolah-olah ada di dalam sebuah ruangan bengkel sticker, serta memiliki fitur capture, rotate dan hanya menampilkan sticker motor yang sudah disediakan dalam aplikasi. Penelitian ini menggunakan bahasa pemograman C\# (C Sharp) dan aplikasi game engine unity 3D 5.6.2f1. Dengan adanya aplikasi yang di tampilkan dalam bentuk 3D maka hasil desain dari sticker motor mendapatkan daya tarik lebih terhadap peminatnya, dari hasil pengujian aplikasi sticker motor scoopy ini memiliki persentase rata-rata $99 \%$.
\end{abstract}

(C) This work is licensed under a Creative Commons AttributionShareAlike 4.0 International License.

\section{Koresponden:}

Ana Yulianti,

Program Studi Teknik Informatika, Fakultas Teknik

Universitas Islam Riau

Email : ana.yulianti@eng.uir.ac.id

\section{PENDAHULUAN}

CV Upgrade Graphic Design perusahaan yang bergerak dalam bidang periklanan, utamanya di material cutting sticker, sticker printing, one way, vision, sticker sablon, sticker poliplex, dan segala jenis sticker. Didukung oleh sumber daya manusia yang terampil dan profesional di bidangnya. Saat ini banyak masyarakat yang menggunakan sticker motor khususnya dikalangan remaja sebagai media untuk menghias beberapa barang mereka seperti helm, motor, hingga mobil agar tampak lebih keren dan berbeda.

Media promosi yang digunakan oleh banyak perusahaan sticker saat ini masih banyak yang hanya menampilkan hasil design dalam bentuk dua dimensi (2D) pada objek motor atau sekedar print out dalam bentuk kertas hingga banyak konsumen yang kurang puas dengan hasil design yang ditampilkan tersebut. Hasil design yang ditampilkan tersebut sangat besar pengaruhnya terhadap daya tarik peminat sticker untuk memperindah motor mereka. 
Hasil design yang di tampilkan dalam bentuk 3D dan seolah-olah ada di dalam sebuah ruangan bengkel sticker, serta memiliki fitur capture, rotate dan sticker motor yang sudah disediakan dalam aplikasi dan menggunakan bahasa pemograman C\# (C Sharp).

Dengan adanya aplikasi yang di tampilkan dalam bentuk 3D maka hasil desain dari sticker motor mendapatkan daya tarik lebih terhadap peminatnya. Dengan begitu, konsumen sebagai peminat sticker motor akan lebih puas dengan hasil design yang di tampilkan secara menarik, serta mudah digunakan karena dapat berjalan pada smartphone android.

Sistem operasi Android merupakan sistem operasi yang open source, sehingga pengembangan aplikasi menjadi lebih mudah. Hal ini terjadi karena perusahaan Google sebagai pembesutnya memberikan akses ke berbagai code secara bebas, dan perangkat untuk mengembangkan aplikasi untuk Android juga diberikan secara gratis, sehingga semua orang dapat mengembangkan aplikasi untuk sistem operasi Android. Salah satu aplikasi sistem operasi Android yang sering dibuat atau dikembangkan adalah game engine.

Game engine adalah perangkat lunak yang dirancang untuk menciptakan sebuah game. Game engine yang akan digunakan dalam pembuatan aplikasi ini adalah game engine Unity3D, yang mampu mendukung pembuatan game dalam berbagai platform.

\section{METODE PENELITIAN}

\subsection{Tinjauan Pustaka}

Berdasarkan penelitian yang dilakukan oleh Rahmat Juari (2016) membahas tentang aplikasi yang dapat melakukan multi target (menampilkan 2 object sekaligus) dengan adanya aplikasi ini maka peminat design racing stripes atau sticker labih tertarik karena hasil desain dapat ditampilkan dalam bentuk 3D. Pada aplikasi tersbut masih menggunakan markerless atau marker barcode untuk menampilkan suatu object 3D dan hasil design yang di rancang dalam aplikasi tersebut menampilkan design beberapa mobil[3].

Penelitian yang dilakukan oleh Remo Prabowo dkk (2015) dengan aplikasi ini, pengguna dapat mengetahui keragaman rumah tradisional Indonesia melalui kamera smartphone android dengan menggunakan KTP sebagai marker yang dapat memudahkan pengguna dalam mengakses aplikasi. Aplikasi yang dibuat berhasil memodernisasi media pengenalan rumah adat Indonesia dan meningkatkan antusiasme masyarakat untuk mengenal rumah adat Indonesia, adanya Interaksi menggunakan tombol yang disediakan pada Aplikasi ini memudahkan User untuk menjalankan aplikasi[5].

Penelitian berikutnya yang dilakukan oleh Juan Nicky Aristo Pattymahu dan Oktoverano Lengkong (2016) penelitian ini membuat tentang aplikasi virtual eksplorasi RSUP Prof Dr. R. D. Kandou Manado diharapkan dapat memudahkan pengunjung dalam mencari ruangan atau lokasi yang ada di lingkungan rumah sakit. Peneliti akan membuat aplikasi virtual eksplorasi ini menggunakan Google Sketchup sebagai tool untuk pemodelan objek 3D bangunan rumah sakit dan Unity 3D yang akan digunakan sebagai game engine. Penelitian ini akan menghasilkan aplikasi virtual eksplorasi di RSUP Prof Dr. R. D. Kandou Manado menggunakan game engine berbasis Android[9].

\subsection{Tinjauan Pustaka}

Dalam melakukan proses pembuatan aplikasi, sangat diperlukan sebuah data yang benar, dan terbukti keakuratannya. Maka dari itu, untuk mendapatkan data yang benar dan akurat, teknik pengumpulan data dilakukan dengan cara sebagai berikut :

1. Wawancara (Interview)

Wawancara dilakukan dengan salah satu karyawan yang bekerja design grafis di CV. Upgrade Graphic Design. Dalam proses wawancara tersebut dilakukan proses tanya jawab mengenai hal-hal terkait dengan proses pemilihan stiker.

2. PengumpulanData

Data-data yang diperlukan akan dikumpulkan berdasarkan hasil dari wawancara dan melakukan survei ke lapangan. Data yang diperoleh yaitu beberapa gambar stiker. Dari 
hasil pengumpulan data, data tersebut akan digunakan sebagai acuan untuk membangun sistem baru yang dapat diimplementasikan.

3. Penelitian Kepustakaan

Melakukan penelitian di perpustakaan dengan cara mencari buku dan literatur yang berhubungan dengan masalah yang di teliti. Hal ini sangat berguna untuk pedoman dan referensi bagi penulis.

\subsection{Konsep Teori}

\subsubsection{Sticker}

Secara umum sticker adalah lembaran kecil kertas atau plastik yang ditempelkan atau sticker juga sering dikatakan suatu bahan yang dapat menempel dengan sendiri atau memiliki perekat.

\subsubsection{Skuter Matik}

Tipe ini adalah tipe sepeda motor otomatis yang tidak menggunakan operan gigi manual dan hanya cukup dengan satu akselerasi, sepeda motor ini memiliki kapasitas silinder (CC) kecil dan posisi pengemudi yang tegak, ukuran sepeda motor ini lebih kecil dan ringan daripada tipe bebek.

\subsubsection{Android}

Android merupakan sistem operasi yang bebasis Linux. Android dikembangkan oleh Google Inc pada saat Google membeli pertama kali pada tahun 2005. Google secara resmi pada tahun 2007 Open Handset Allience mengumumkan bahwa Android telah menjadi open source, sehingga semua orang dapat mengembangkan aplikasi untuk Android. Setelah itu, pada tahun 2008 Android SDK 1.0 dirilis untuk pertama kalinya[9].

\subsubsection{Aplikasi Game Engine Unity 3D}

Unity Engine suatu game engine yang terus berkembang. Engine ini merupakan salah satu game engine dengan lisensi source proprietary, namun untuk lisensi pengembangan dibagi menjadi 2, yaitu free (gratis) dan berbayar sesuai perangkat target pengembangan aplikasi (Berta Sihite, Febriliyan Samopa, 2013)[3].

\subsubsection{Tiga Dimensi (3D)}

3D adalah sebuah objek yang memiliki panjang, lebar, dan tinggi yang memilki bentuk. 3D tidak hanya digunakan dalam matematika dan fisika saja melainkan pada bidang grafis, seni, animasi, komputer dan lainlain. 3D dapat menggambarkan setiap objek yang terjadi pada tiga sumbu sistem koordinat cartesian[9].

\subsubsection{Aplikasi Blender 3D}

Menurut Lance Flavell (2010) Blender merupakan paket aplikasi pemodelan dan animasi tiga dimensi yang memiliki berbagai fungsi yang tidak dimiliki aplikasi tiga dimensi lainnya[3].

\subsubsection{C\# ( C Sharp)}

C\# (dibaca: C sharp) merupakan sebuah bahasa pemrograman yang berorientasi objek yang dikembangkan oleh Microsoft sebagai bagian dari inisiatif kerangka .NET Framework. Bahasa pemrograman ini dibuat berbasiskan bahasa $\mathrm{C}++$ yang telah dipengaruhi oleh aspek - aspek atau pun fitur bahasa yang terdapat pada bahasa - bahasa pemrograman lainnya seperti Java, Delphi, Visual Basic dan lain - lain dengan beberapa penyederhanaan[1].

\section{HASIL DAN PEMBAHASAN}

\subsection{Analisa Sistem yang Sedang Berjalan}

Konsumen datang terlebih dahulu ke toko CV Upgrade Graphic design melihat dan memilih beberapa stiker dalam bentuk print out (2D). Setelah memilih, konsumen memesan sticker tersebut 
dan menunggu 1 - 2 hari proses mencetak stiker, stiker selesai dicetak barulah stiker dipasangkan oleh karyawan upgrade ke body motor scoopy konsumen. Analisa dapat dilihat pada gambar 1.

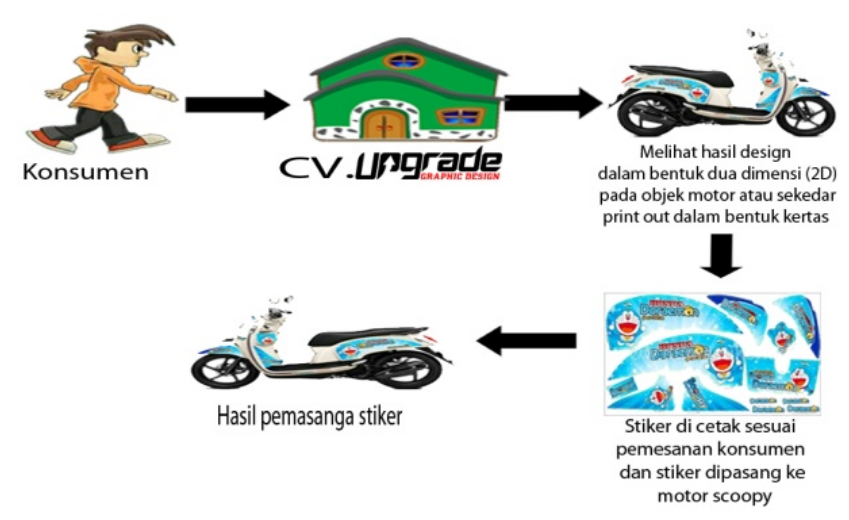

Gambar 1. Halaman Utama

\subsection{Pengembangan Sistem}

Tujuan dari aplikasi yang dibuat yaitu agar dapat menghasil suatu aplikasi yang mampu menampilkan hasil sticker dalam bentuk objek 3D dan memilih sticker yang sudah ada. Pengembangan multimedia agar dapat dimasukkan dalam pembelajaran harus melalui tahapan tahapan yang terancang dengan baik dan runtut agar produk multimedia yang dihasilkan memiliki kualitas yang baik dan tepat digunakan dalam pembelajaran. Pengembangan dapat dilihat pada gambar 2.

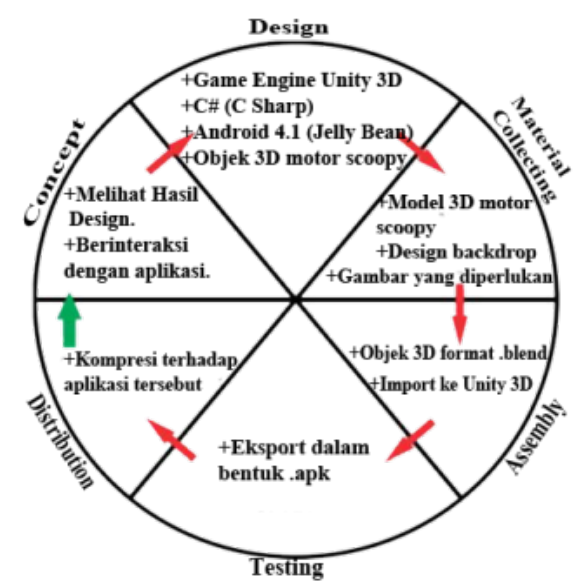

Gambar 2. Metode Pengembangan MDLC

\subsection{Desain Logika Program}

Perancangan aplikasi pada penelitian ini menggunakan flowchart yang digunakan untuk menunjukan alur kerja atau apa saja yang akan dikerjakan oleh sistem secara keseluruhan. Secara umum alur sistem aplikasi sticker motor scoopy berbasis android ini adalah sebagai berikut : 


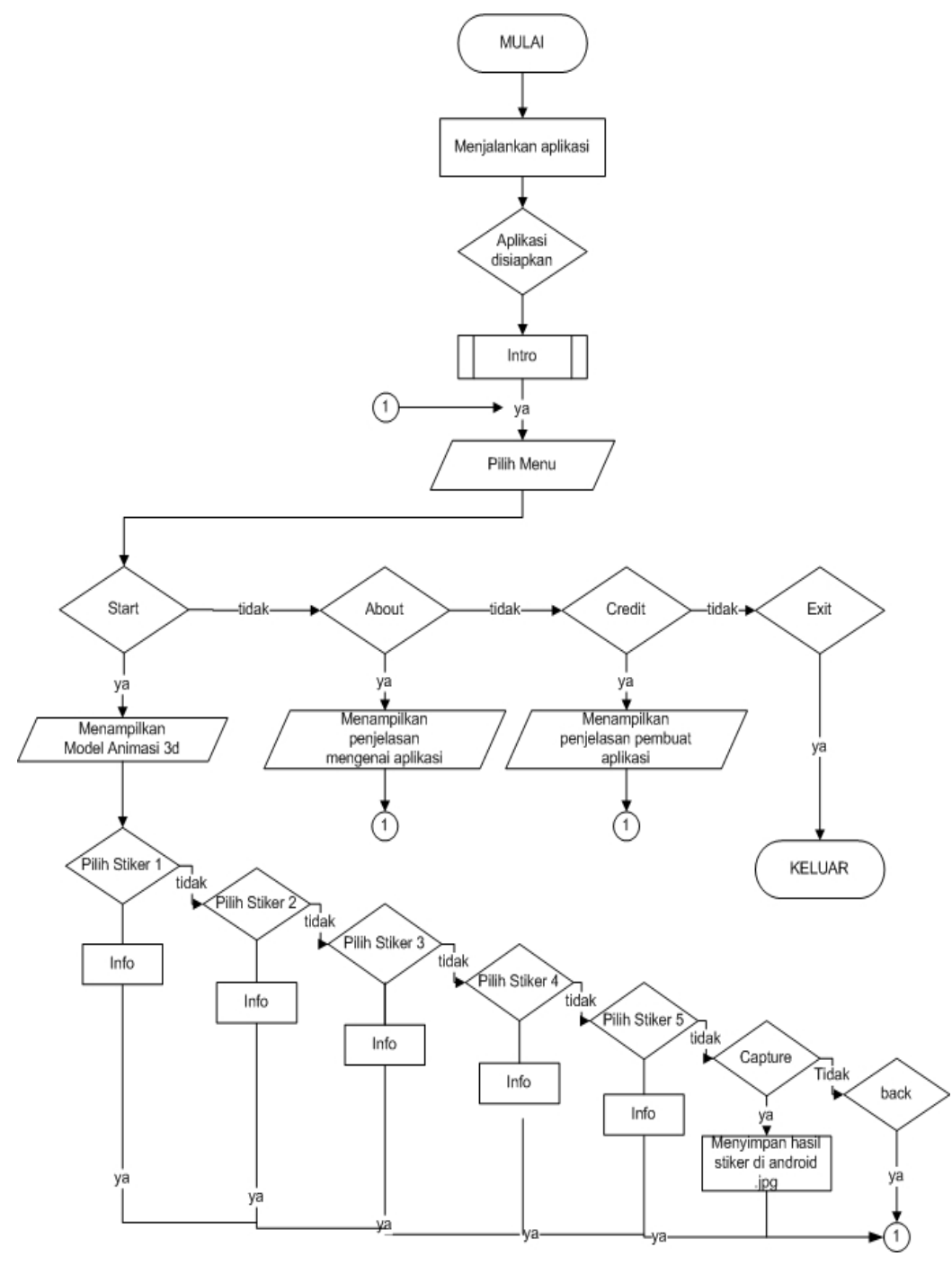

Gambar 3. Flowchart Aplikasi Sticker Motor Scoopy

\subsection{Modeling Animasi 3D dengan Software Blender}

Proses modeling animasi 3D motor scoopy menggunakan software Blander

1. Tampak Samping, Depan dan Belakang Objeck 3D Motor Scoopy Gambaran modeling motor scoopy tampak samping, depan dan belakang dapat dilihat pada gambar 4 .
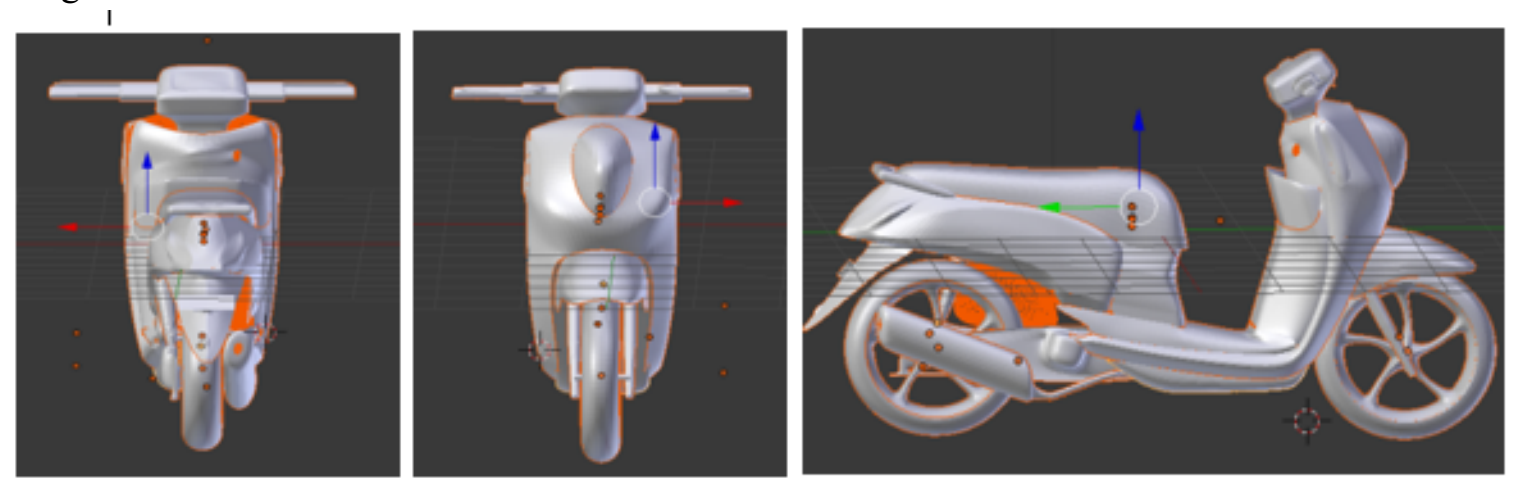

Gambar 4. Modeling Objeck 3D Motor Scoopy 


\subsection{Sequence Diagram}

Sequence diagram pada aplikasi sticker ini dapat dilihat pada gambar 5 .

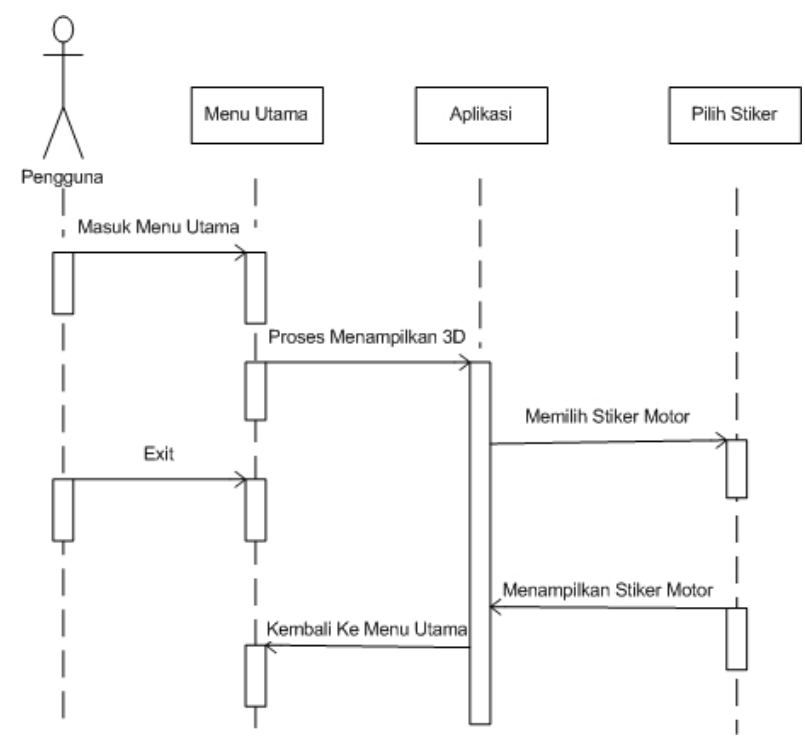

Gambar 5. Halaman Detail Data Kos

\subsection{Tampilan Awal Aplikasi Sticker Motor Scoopy}

Gambar 6 merupakan tampilan halaman awal dari aplikasi saat aplikasi dijalankan, tampilan logo aplikasi tersebut akan hilang setelah kurang lebih 10 detik.

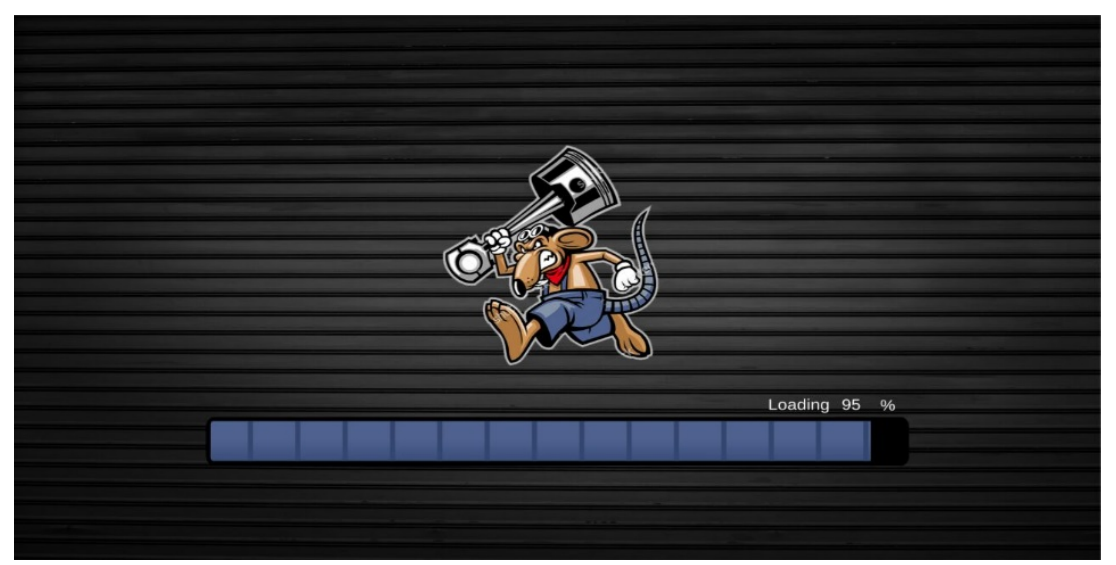

Gambar 6. Halaman Pemesanan Sementara

Setelah logo tersebut hilang maka pengguna akan dihadapkan dengan halaman menu intro aplikasi sticker motor scoopy yang dapat dilihat pada gambar 7 . 


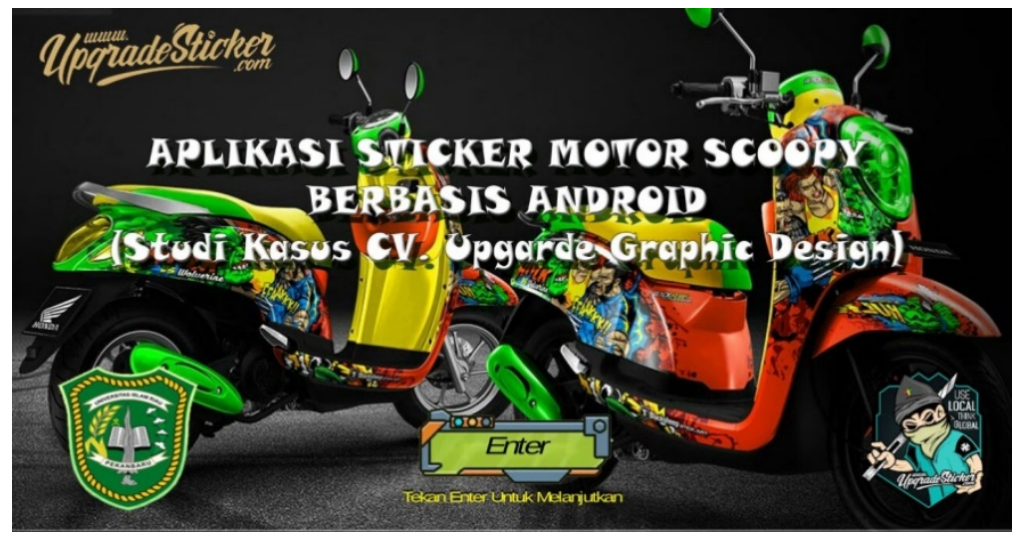

Gambar 7. Tampilan Intro Aplikasi

Gambar 8 adalah tampilan menu intro dari aplikasi setelah aplikasi dijalankan, pada halaman tersebut terdapat button yaitu button enter untuk masuk ke menu utama.

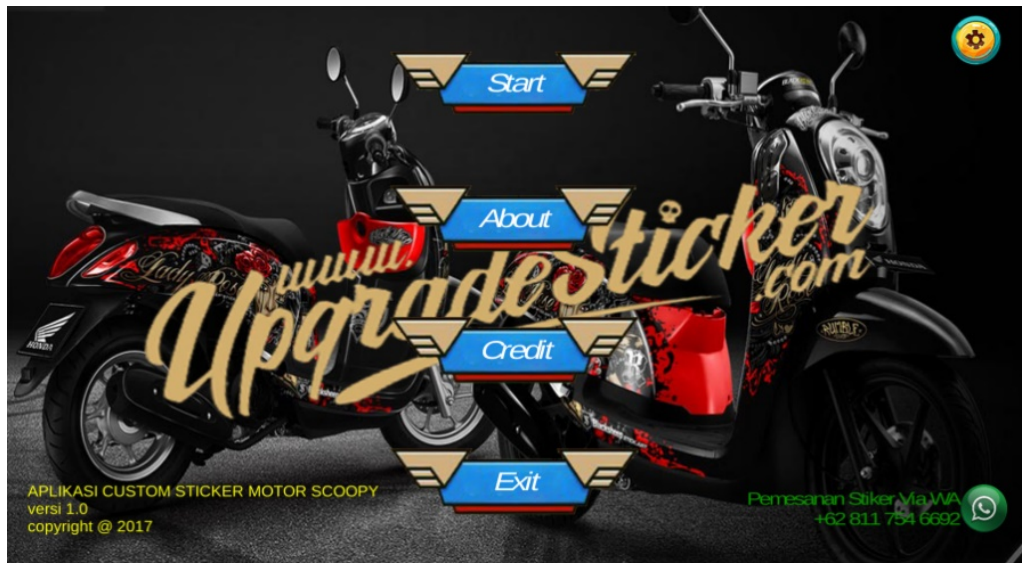

Gambar 8. Tampilan Menu Utama Aplikasi

Gambar 9 adalah tampilan menu utama dari aplikasi setelah aplikasi dijalankan, pada halaman tersebut terdapat beberapa button yaitu button start untuk masuk menampilkan objeck 3D motor scoopy dan memilih stiker yang sudah disediakan oleh aplikasi, button about yang berguna untuk menampilkan penjelasan mengenai aplikasi, button credit berguna untuk menampilkan penjelasan mengenai identitas pembuat aplikasi dan button exit untuk keluar atau menghentikan aplikasi.

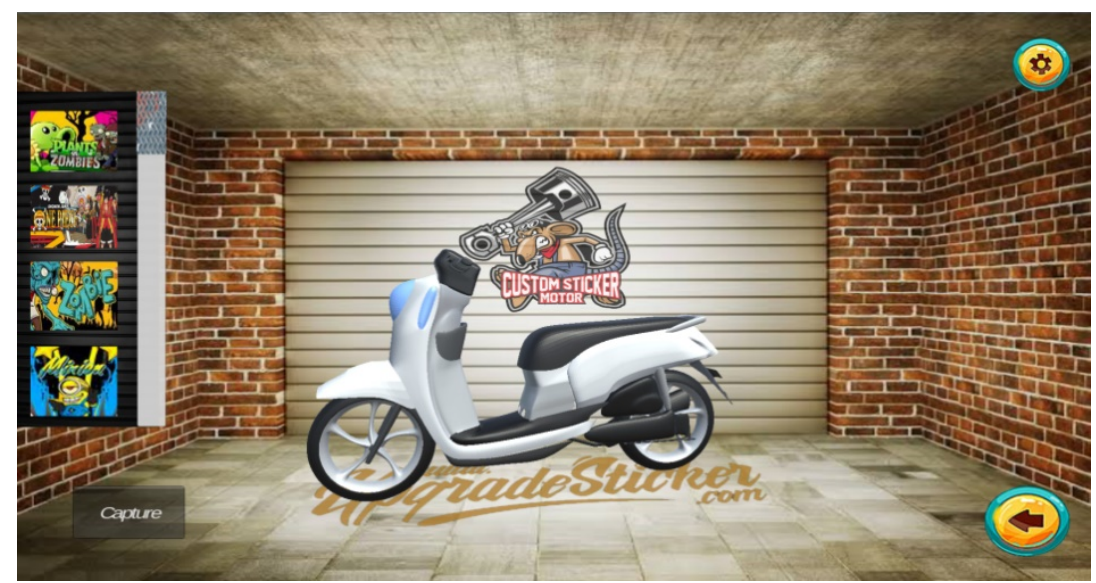

Gambar 9. Tampilan Menu Start Aplikasi 
Ketika menu start ditekan menunggu beberapa detik untuk masuk ke dalam menu start maka akan muncul objek 3D motor scoopy bisa rotate menggunakan jari pengguna (touchscreen).

\subsection{Tampilan Menu Stiker}

1. Tampilan Stiker 1 (Plants VS Zombie)

Tampilan stiker pertama ketika diklik maka muncul button info pada pojok kiri atas dan stiker dari polos akan berganti pada bagian body samping kiri kanan, pada bagian body depan dan pada spakbor depan motor scoopy. Dapat dilihat pada gambar 10 dibawah ini.

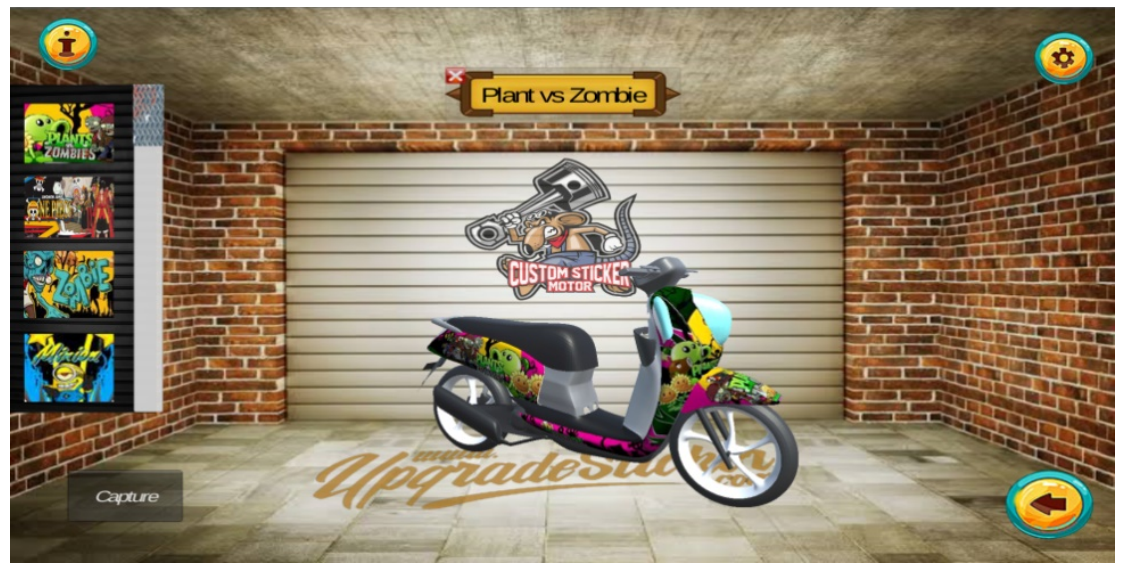

Gambar 10. Tampilan Stiker 1

2. Tampilan Info Stiker 1 (Plants VS Zombie)

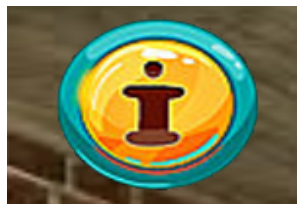

(a)

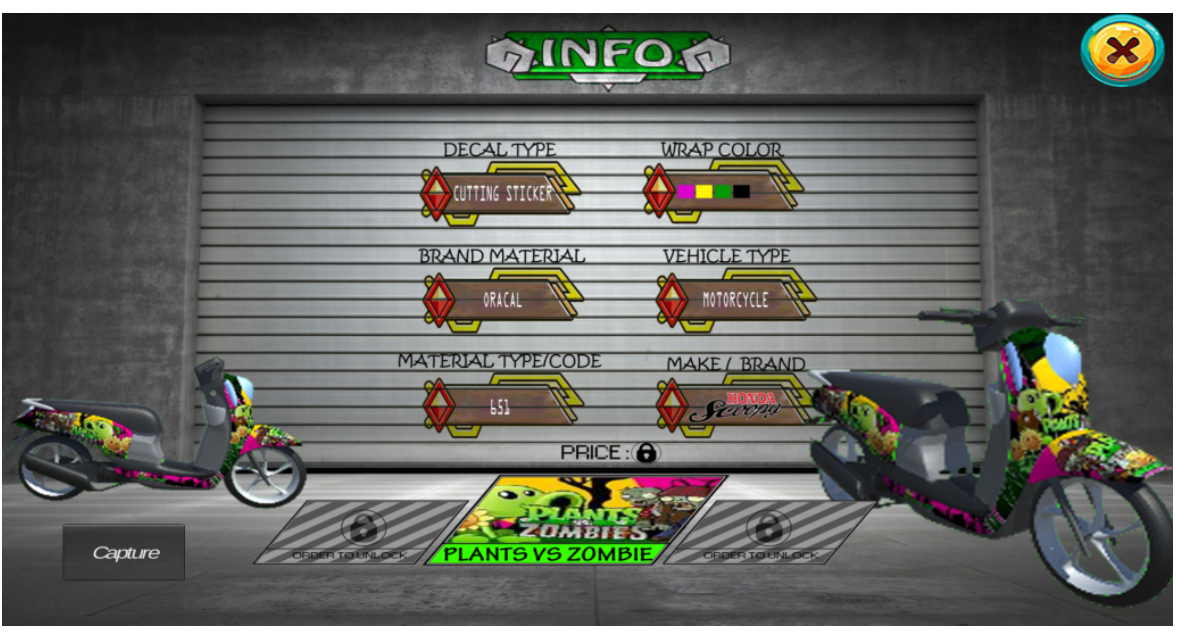

(b)

Gambar 11. Tampilan Info Stiker (a. Sebelum) (b. Sesudah) 
Gambar 11 adalah tampilan info stiker 1 dari aplikasi setelah button info diklik seperti info : Decal Type, Brand Material, Code Material, Wrap Color,Vehicle Type,Make / Brand. Tekan button X pada pojok kanan atas untuk keluar dari tampilan info.

\subsection{Tampilan Hasil Button Capture}

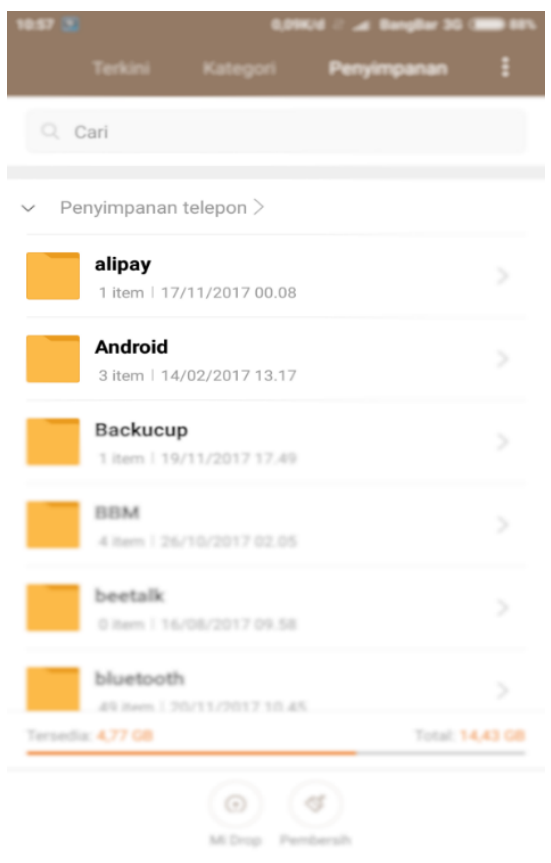

(a)

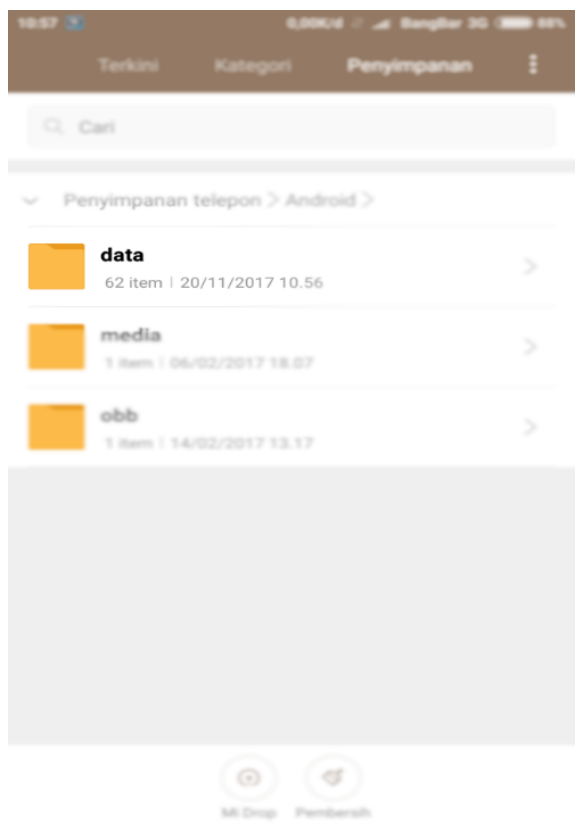

(b)

\section{Scoopy_20171120_105651.jpg}

2,64 MB | 20/11/2017 10.56

\section{Scoopy_20171120_105652.jpg}

$2,64 \mathrm{MB} \mid 20 / 11 / 201710.56$

(c)

Gambar 12. Hasil Button Capture (a) (b) (c)

Gambar a merupakan tampilan hasil button capture terlebih dahulu kita masuk ke dalam berkas pada android atau penyimpanan file. Pilih penyimpanan telepon dan pilih folder android. Pilih folder data seperti gambar b. Gambar c merupakan hasil dari button capture nama file capture berdasarkan tanggal dan pukul saat pengambilan capture dalam format .jpg.

\section{KESIMPULAN}

Berdasarkan hasil analisa dan pengujian pada penelitian aplikasi sticker motor scoopy, maka dapat diambil kesimpulan sebagai berikut :

1. Pembuatan aplikasi model 3D interaktif ini melalui beberapa tahap produksi diantaranya modelling, texturing, coding dan rendering. 
2. Aplikasi sticker motor scoopy ini sebagai acuan untuk memilih stiker motor scoopy bagi penggunanya.

3. Aplikasi sticker motor scoopy ini hanya menampilkan sticker motor yang sudah di sediakan aplikasi.

4. Berdasarkan hasil pengujian yang dilakukan pada kuisioner memiliki performance baik dengan nilai persentase rata-rata sebesar 99\%, maka aplikasi tersebut layak untuk dipublikasikan.

\section{DAFTAR PUSTAKA}

[1] Adelia, Setiawan., Jimmy, 2011, Implementasi Customer Relationship Management (CRM) pada Sistem Reservasi Hotel berbasisi Website dan Desktop, Jurnal Sistem Informasi, Vol. 6, No.2, Hal $113-126$.

[2] A.S, Rosa dan Shalahuddin, M., 2104, Rekayasa Perangkat Lunak, Informatika, Bandung.

[3] Juari, Rahmat., 2016, Pemanfaatan Augmented Reality Untuk Menampilkan Hasil Design Racing Stripes Dalam Bentuk 3D (Study Kasus: CV. Upgrade Grafhic Design), Skripsi, Jurusan Teknik Informatika, STMIK Amik Riau, Pekanbaru.

[4] Kadir, Abdul., 2013, Pengenalan Algoritma, Ed.1, ANDI, Yogyakarta.

[5] Prabowo, Remo, Dkk., 2015, Pengenalan Rumah Adat Indonesia Berbasis Augmented Reality Dengan Memanfaatkan KTP Sebagai Marker, SNATIF, ISBN: 978-602-1180-21-1, Hal 51-58.

[6] Rahman, Abdur., 2014, Rancang Bangun Aplikasi Informasi Universitas Bengkulu Sebagai Panduan Pengenalan Kampus Menggunakan Metode Markerless Augmented Reality Berbasis Android, Skripsi, Program Studi Teknik Informatik. Fakultas Teknik, Universitas Bengkulu, Bengkulu.

[7] Sari, Julia Purnama., 2014, Rancang Bangun Aplikasi Layanan Berbasis Lokasi Dengan Penerapan Augmented Reality Menggunakan Metode Markerless Berbasis Android (Studi Kasus : Pencarian Perangkat Daerah Kota Bengkulu), Skripsi, Program Studi Teknik Informatika, Fakultas Teknik, Universitas Bengkulu, Bengkulu.

[8] Suryanto, Tomi, Dkk., 2014, Rancang Bangun Virtual Gamelan Mobile Manggunakan Augmented Reality, JURNAL DASI, ISSN: 1411-3201, Vol.15, Hal 38-47.

[9] Pattymahu, Juan Nicky Aristo., Lengkong, Oktoverano., 2016, Aplikasi Virtual Eksplorasi RSUP Prof DR. R. D. KANDOU MANADO Menggunakan Game Engine Berbasis Android, ISSN : 2302-3805, Hal 31-36. 